\title{
Association of functional capacity with risk of falling in the older adults in emergency service
}

\author{
Associação da capacidade funcional com o risco de queda em idosos em serviço de \\ emergência
}

Juliane de Fátima Santos Antunes ${ }^{1}$, Cássia Regina Vancini Campanharo ${ }^{1}$, Maria Carolina Barbosa Teixeira Lopes ${ }^{1}$, Ruth Ester Assayag Batista ${ }^{1}$, Meiry Fernanda Pinto Okuno ${ }^{1}$

Objective: to associate the functional capacity with the risk of falling of the older adults in emergency service. Methods: this is a cross-sectional and analytical study, in which 101 individuals, aged 60 years old and older, of both genders, admitted to the Emergency Department. The Katz and Lawton/Brody scales were used to evaluate functional capacity and, the Downton scale was used for the risk of fallings. The Fisher-Freeman-Halton test was used to associate functional capacity with the risk of falling. Results: $32.7 \%$ of the older adults were independent in one function and dependent on five basic functions of daily living, 89.1\% were totally dependent on instrumental activities and $64.4 \%$ had a high risk of falling. There was no statistically significant association between the Katz, Lawton/Brody, and Downton scales. Conclusion: functional capacity was not associated with the risk of falls in the study population.

Descriptors: Frail Elderly; Population at Risk; Geriatric Nursing.

Objetivo: associar a capacidade funcional com o risco de queda de idosos em serviço de emergência. Métodos: estudo transversal e analítico, no qual foram incluídos 101 indivíduos, com idade igual ou superior a 60 anos, de ambos os sexos, internados no Serviço de Emergência. Para avaliar a capacidade funcional, utilizaram-se as escalas de Katz e Lawton/Brody; e, para o risco de queda, a escala de Downton. Para associar a capacidade funcional com o risco de queda, utilizou-se o teste de Fisher-Freeman-Halton. Resultados: 32,7\% dos idosos foram independentes em uma função e dependentes em cinco funções básicas de vida diária, 89,1\% foram totalmente dependentes para atividades instrumentais e 64,4\% obtiveram alto risco de queda. Não houve associação estatisticamente significativa entre as escalas de Katz, Lawton/Brody e Downton. Conclusão: a capacidade funcional não se associou ao risco de queda na população estudada.

Descritores: Idoso Fragilizado; População em Risco; Enfermagem Geriátrica.

\footnotetext{
${ }^{1}$ Universidade Federal de São Paulo, Escola Paulista de Enfermagem. São Paulo, SP, Brazil. 


\section{Introduction}

The population aged 60 years old and older is growing faster in Brazil when compared to individuals of other age groups, causing a change in population dynamics. The estimate for 2040 indicates that the older adult population may represent $23.8 \%$ of the Brazilian population, a proportion of 153 elderly people per 100 young people ${ }^{(1)}$. The World Health Organization considers older individuals aged from 65 in developed countries and 60 in developing countries ${ }^{(1)}$.

This increase in life expectancy has been due to the control of epidemics and to better socioeconomic conditions, followed by the prevalence of chronic non-communicable diseases, which are causes of disability, dependence, and death in this people ${ }^{(1-2)}$. As a result, the demand for health services, hospitalizations, and length of hospital stay increased in the older adults when compared to other age groups ${ }^{(2)}$.

The physiological and biological changes that occur in the aging process, such as decreased muscle mass, mainly in the lower limbs, decreased visual and auditory acuity, and balance deficit, increase the risk of falling in the older population, resulting in loss of functionality and decrease quality of life $\mathrm{e}^{(3)}$.

Therefore, functional capacity may change during the hospitalization of the older person, because it is a complex event at a time of fragility and imbalance, when he is removed from the environment and transferred to an environment that is often seen as adver$\mathrm{se}^{(4)}$.

In the hospital environment, the level of dependence is often related to the patient's prognosis and can be used to differentiate the type of care that each patient should receive ${ }^{(4)}$. This level of dependence is directly related to the functional capacity of the older adult, that is, their ability to perform daily activities independently and to take care of themselves that can be measured through standard instruments that verify the performance of the older person in the basic activities of life ${ }^{(5)}$ and instrumental activities ${ }^{(2)}$.

Also, another factor that can change the func- tional capacity of the older adult is the falling, being an unintentional change of the body to a lower position than the initial one, without the capacity of correction in time enough, being able to be caused by multifactorial questions, as well as the physiological changes related to aging, considered intrinsic factor, and to the extrinsic reasons, such as the environment to which the older adults are exposed ${ }^{(3)}$.

The work of the nursing team should be centered on the educational process with the older people and their relatives, aiming at their functional independence, the prevention of secondary complications and their adaptation and the family to the new situation of functional impairment ${ }^{(2)}$, besides promoting health and well-being to this population ${ }^{(1)}$. The evaluation of the functional capacity of the elderly person and the risk of falling allow the identification of demands for nursing care and the multidisciplinary team that, once worked, can minimize or avoid the functional loss and the occurrence of falling.

Thus, the objective of this study was to associate functional capacity with the risk of falling of the older adults in emergency service.

\section{Methods}

This is a cross-sectional study carried out at the Emergency Department of São Paulo Hospital between July and September 2016. The sample consisted of 101 older individuals, aged 60 years old and over, of both genders and hospitalized in the Service with or without caregiver, who sought the service with clinical and surgical complaints and agreed to voluntarily participate in the research.

Data collection was performed five times per week. Those older individuals who met the inclusion criteria were invited to be part of the study and interviewed individually. The instrument was read by the researcher, in a single moment, with an average duration of 30 minutes.

A structured questionnaire was used, with information on age, gender, education level, marital 
status, occupation, skin color, use of medication, comorbidities, presence of caregiver, presence of pain (yes or no, location and duration) and history of their last year. The evaluation of the functional capacity of the older person to perform basic activities of daily living was carried out using the Katz Scale, translated, adapted and validated in Brazil (Chronbach's alpha of 0.80 to 0.92$)^{(5)}$, which evaluates the level of independence or functional dependence of the older person to perform the following activities: bathing, dressing, feeding, transfer, going to the bathroom and continence. The options of answers are dichotomous and the score varies from 0 to 6 points: 0 to independent individual in all six basic activities; 1 to independent in five functions and dependent on one function; 2 to independent in four functions and dependent in two; 3 to independent in three functions and dependent in three; 4 to independent in two functions and dependent in four; 5 to independent in one function and dependent on five functions and 6 to dependent on all six basic activities of daily living ${ }^{(2,5)}$.

Lawton and Brody's Scale ${ }^{(2)}$ was used to evaluate the instrumental activities of daily living, translated, adapted and validated in Brazil (Chronbach's Alpha 0.94), composed of the following activities: telephone use, travel, preparing meals, doing household chores, taking medications, and handling money. The response options are dichotomous and each scale item gets from 3 points (independent) to 1 point (totally dependent), ranging from 7 to 21 points, where the higher the score, the more independent the patient is ${ }^{(2,5)}$.

The risk of falling in the older participants was evaluated by the Downton Scale, translated, adapted and validated in Brazil, which includes five variables: previous falls; use of medications; presence of sensory deficit; mental state of the older person and type of gait. The response options are dichotomous and their scores range from 0 to 11 points, and a score equal or greater than three indicates that the elderly person has a high risk of falling ${ }^{(3)}$.

Data analysis was performed by the Statistical Package for Social Sciences, version 19. The descrip- tive analysis was used for sociodemographic, clinical characterization and the presence of caregiver. For the numerical variables, mean, standard deviation, median, minimum and maximum were calculated; and for categorical variables, frequency and percentage were calculated.

The Chi-Square test and, when necessary, the Fisher's Exact test were used to relate the categorical variables to the scales ${ }^{(2-3)}$. The Analysis of Variance was applied to relate the age to the scales ${ }^{(2-3,5)}$. A significance level of $5 \%(\mathrm{p}<0.05)$ was considered for all analyzes. To take advantage of the Variance Analysis, normality was tested through the Kolmogorov-Smirnov Test. Also, the homogeneity of the variances (homoceidosity) was verified.

This study was approved by the Ethics Committee in Research of the Federal University of São Paulo, according to opinion no 1,601,766.

\section{Results}

The mean age of the patients $(n=101)$ was $75 \pm 9.4$ years old, most of them were female, 55 (54.5\%); white skin color, 64 (64.0\%); married, 57 (56.4\%); retired, 89 (88.1\%); with incomplete elementary school, 63 (62.4\%); and with a caregiver, 60 (59.4\%).

The most prevalent comorbidities in the patients in this study were systemic arterial hypertension, 70 (69.3\%); diabetes mellitus, 46 (45.5\%); respiratory tract disease, 33 (32.7\%); musculoskeletal disease, 26 (25.7\%); dyslipidemia, 25 (24.8\%); and renal disease, 25 (24.8\%). The most used drugs were: antihypertensive drugs, 70 (78.7\%); analgesic, 48 (53.9\%); antiulcerous, 50 (56.2\%); hypoglycaemic, 37 (41.6\%); and hypolipidemic, 25 (28.1\%).

Of the interviewees, 96 (95\%) reported not practicing any physical activity, 36 (35.6\%) fell once in the last year and $48(47.5 \%)$ had at least one fall this year. Also, $68(67.3 \%)$ of the patients reported pain, of which $48(72.7 \%)$ of them had it for more than six months; and the region most frequently affected by 
pain complaints were in the lower limbs, 37 (56.1\%); and back pain 22 (33.3\%).

The dependency levels for daily and instrumental activities were not statistically significant with the risk of falling (Table 1).

Table 1 - Association of functional capacity with fall risk $(\mathrm{n}=101)$

\begin{tabular}{|c|c|c|c|c|}
\hline \multirow{3}{*}{ Functional capacity } & \multicolumn{2}{|c|}{ Fall risk } & Total & \multirow{3}{*}{$\mathbf{p}^{*}$} \\
\hline & High risk & Low risk & \multirow{2}{*}{ n (\%) } & \\
\hline & n (\%) & n (\%) & & \\
\hline
\end{tabular}

Activities of daily living (Levels)

\begin{tabular}{|c|c|c|c|}
\hline 0 & $1(14.3)$ & $6(85.7)$ & $7(100.0)$ \\
\hline 1 & $10(52.6)$ & $9(47.4)$ & $19(100.0)$ \\
\hline 2 & $4(66.7)$ & $2(33.3)$ & $6(100.0)$ \\
\hline 3 & $8(80.0)$ & $2(20.0)$ & $10(100.0)$ \\
\hline 4 & $4(57.1)$ & 3 (42.9) & 7 (100.0) \\
\hline 5 & 23 (69.7) & $10(30.3)$ & $33(100.0)$ \\
\hline 6 & 15 (78.9) & 4 (21.1) & $19(100.0)$ \\
\hline
\end{tabular}

Instrumental activities of daily living

\begin{tabular}{lllll} 
Total dependency & $60(66.7)$ & $5(45.5)$ & $65(64.4)$ & 0.192 \\
Partial dependency & $30(33.3)$ & $6(54.5)$ & $36(35.6)$ & \\
\hline *Fisher-Freeman-Halton test & & &
\end{tabular}

The older adults with greater dependence for basic activities of daily living had a higher percentage of caregivers $(\mathrm{p}=0.018)$. Both the older individual and those most dependent on basic activities had a high percentage of pain lasting six months or more $(p=0.021)$, and these individuals were mainly dependent on bathing.

The level of dependence for instrumental activities was not statistically significant with sociodemographic variables, medication use, physical activity and presence of pain.

Table 2 shows that patients with total dependence for instrumental activities of daily living presented higher percentages than those with the presence of caregiver. Individuals with partial dependence presented higher percentages of dyslipidemia and diseases of the urinary tract, with a statistically significant association.
Table 2 - Association between instrumental activities of daily living and presence of caregiver, dyslipidemia, and diseases of the urinary tract $(n=101)$

\begin{tabular}{|c|c|c|c|c|}
\hline \multirow[b]{2}{*}{ Variables } & \multicolumn{3}{|c|}{$\begin{array}{l}\text { Instrumental Activities of Daily } \\
\text { Living }\end{array}$} & \multirow[b]{2}{*}{$\mathbf{p}$} \\
\hline & $\begin{array}{c}\text { Total } \\
\text { dependency } \\
\text { n (\%) }\end{array}$ & $\begin{array}{l}\text { Partial de- } \\
\text { pendency } \\
n(\%)\end{array}$ & $\begin{array}{l}\text { Total } \\
\text { n (\%) }\end{array}$ & \\
\hline \multicolumn{5}{|c|}{ Presence of caregiver } \\
\hline Yes & $58(64.4)$ & $2(18.2)$ & $60(59.4)$ & $0.006^{*}$ \\
\hline No & $32(35.6)$ & $9(81.8)$ & $41(40.6)$ & \\
\hline \multicolumn{5}{|c|}{ Dyslipidemia } \\
\hline No & $72(80)$ & $4(36.4)$ & $76(75.2)$ & $0.004^{\dagger}$ \\
\hline Yes & $18(20)$ & $7(64.6)$ & 25 (24.8) & \\
\hline \multicolumn{5}{|c|}{ Diseases of the urinary tract } \\
\hline No & $89(98.9)$ & $9(81.8)$ & $98(97.0)$ & $0.031^{\dagger}$ \\
\hline Yes & $1(1.1)$ & $2(18.2)$ & $3(3.0)$ & \\
\hline
\end{tabular}

There was a statistically significant association between the risk of falling and age, presence of hypertension, dementia, and history of falls in the last year. Older people with a high risk of falling had older age, higher percentages of dementia, Systemic Arterial Hypertension and fall in the last year (Table 3).

Table 3 - Variables associated with the Risk of Falls $(n=101)$

\begin{tabular}{|c|c|c|c|c|}
\hline \multirow[b]{2}{*}{ Variables } & \multicolumn{2}{|c|}{ Risk of Falls } & \multirow{2}{*}{$\begin{array}{l}\text { Total } \\
\text { n (\%) }\end{array}$} & \multirow[b]{2}{*}{$\mathbf{p}$} \\
\hline & $\begin{array}{l}\text { High } \\
\text { n (\%) }\end{array}$ & $\begin{array}{c}\text { Low } \\
\text { n (\%) }\end{array}$ & & \\
\hline \multicolumn{5}{|c|}{ Age (years old) } \\
\hline Mean (SD) & $77(9.3)$ & $71(8.4)$ & $75(9.4)$ & $0.003^{*}$ \\
\hline \multicolumn{5}{|c|}{ Systemic Arterial Hypertension } \\
\hline No & $14(21.5)$ & $17(47.2)$ & $31(30.7)$ & $0.007^{\dagger}$ \\
\hline Yes & $51(78.5)$ & $19(52.8)$ & $70(69.3)$ & \\
\hline \multicolumn{5}{|l|}{ Dementia } \\
\hline No & $48(73.8)$ & $34(94.4)$ & $82(81.2)$ & $0.011^{\dagger}$ \\
\hline Yes & $17(26.2)$ & $2(5.6)$ & $19(18.8)$ & \\
\hline \multicolumn{5}{|c|}{ Fall history in the last year } \\
\hline Yes & $28(43.1)$ & $8(22.2)$ & $36(35.6)$ & $0.036^{\dagger}$ \\
\hline No & 37 (56.9) & $28(77.8)$ & $65(64.4)$ & \\
\hline
\end{tabular}




\section{Discussion}

The limitation of the study is because it was performed in a single hospital, belonging to the Brazilian public health system, which may not represent other realities, in addition to the relatively small sample size.

Some characteristics of the sample of this study, such as age, most women, retired, with low education level and caregiver need are similar results to those found in other studies ${ }^{(6-7)}$. The age range found is in accordance with the demographic transition observed in Brazil. Also, greater longevity has been observed for the female gender ${ }^{(6)}$, which may increase the susceptibility to social factors involved in health promotion in this population.

The main comorbidities observed in the patients of this study were systemic arterial hypertension, diabetes mellitus, and diseases of the respiratory system. It was similar to a study that evaluated functional decline in the older adults after attending emergency services ${ }^{(8)}$. These pathologies are more prevalent in these individuals, possibly due to the increase in life expectancy of the population, and the decrease of infectious diseases allowed amplifying the presence of chronic non-communicable diseases.

Antihypertensive, antiulcer and analgesic were the most used medications. Regarding the medications, a work performed in a basic health unit verified that the drugs most used by the older participants were those that work in the cardiovascular system, the musculoskeletal system and the digestive system, data similar to the present research ${ }^{(9)}$. It should be noted that the occurrence of cardiovascular diseases increases with advancing age and may increase the consumption of medications.

The dependence levels for daily and instrumental activities were not statistically significant with the risk of falling in this population. In the literature, there is no consensus on the association between functional capacity and risk of falls $s^{(10-11)}$. The relationship between falls and functional disability may be subject to cause and effect bias, and falls in the elderly people may result in functional disability, as well as functional limitations may hamper activities and increase the risk of falling ${ }^{(11)}$. The impairment of the functional capacity of individuals over 60 years old directly affects the quality of life, as well as simultaneously reaching the family, the community and the health system in which it is inserted. It is observed that the greater the difficulty in performing the basic activities of daily living, the more dependent this elderly is ${ }^{(12)}$.

Regarding the functionality evaluated by the Katz and Lawton and Brody Scales in this study, the independent elderly people to perform daily life activities had the lowest percentage of caregiver presence, while the most dependent had a higher percentage. It is known that the lower the functionality of the elderly, the greater the need for care, with multiple tasks, on a frequent basis, often requiring the total dedication of the caregiver ${ }^{(12)}$, especially if the older person present some type of dementia, as observed in this study.

The presence of pain limits the autonomy of the elderly, being another event that interferes negatively in the functionality, independence, and quality of life ${ }^{(13)}$. Most of the interviewees reported pain for more than six months, mainly in the lower limbs and back. Chronic pain was also reported by most of the elderly people in a national study ${ }^{(14)}$.

Daily life activities, both instrumental and basic, can be affected by the presence of pain. In this study, individuals with pain greater than six months presented dependence, mainly for bathing. In another study that verified the incidence of chronic pain in the older individuals, it was described that chronic pain was also present in the lives of the participants evaluated, affecting, in some way, the basic activities of daily living ${ }^{(15)}$. This highlights how pain is limiting to the functionality of the elderly person, impairing autonomy and well-being. Therefore, the health professional needs to be aware of the proper evaluation and orientation of these conditions.

Individuals with partial dependence for instrumental activities in this study had higher percentages 
of dyslipidemia and diseases of the urinary tract. In a study carried out in a long-term institution, it was observed that older people with greater dependence to perform basic activities also had urinary incontinence, this fact is also due to the difficulty in reaching the desired place in a timely manner and not only because they are incontinent in fact ${ }^{(15)}$. Also, urinary incontinence is considered a predictor of falls in the elderly population, which may be related to the greater frequency of toilet visits to urinate, increasing the risk of falls ${ }^{(12,16)}$.

The respondents with a high risk of falling were older, with higher percentages of dementia, systemic arterial hypertension and drop in the last year. These results corroborate with those of another Brazilian study carried out in three large hospitals, in which the older adults who are more likely to fall, had a higher prevalence rate of hypertension and cognitive defi$\operatorname{cits}^{(17)}$.

Older adult dependents had higher percentages of the need for the caregiver and dementia. The study concluded that supporting caregivers can contribute to managing the burden of these often familiar individuals, as well as improving the quality of care and their health ${ }^{(18)}$.

Therefore, the use of appropriate instruments can help the nursing and multidisciplinary team to adjust the resources and care in the hospital units that receive this patient profile. Therefore, the importance of the discussion about incapacitating events in this elderly population, which has been growing exponentially, is pointed out since this type of event often contributes to its functional loss, such as the occurrence of falls, which entails restriction of activities, increased dependence, health declines and increases the risk of institutionalization ${ }^{(19)}$.

Independence and autonomy for the longest possible time are goals to be achieved in health care for the older adults ${ }^{(19)}$. The identification of functional capacity and its association with the risk of falling can provide subsidies for professionals and managers who work with this population to provide the creation of strategies for prevention and control of risk factors, promoting a healthy aging.

\section{Conclusion}

There was no association between the functional capacity evaluated by the Katz and Lawton/Brody Scales, with the risk of falling, analyzed by the Downton Scale.

\section{Contributions}

Antunes JFS collaborated in the project design, obtaining and analyzing the data and writing the article. Campanharo CRV, Lopes MCBT, Batista REA, and Okuno MFP contributed with the project design, data analysis and interpretation, article writing and critical review of relevant intellectual content.

\section{References}

1. Miranda GMD, Mendes ACG, Silva ALA. Population aging in Brazil: current and future social challenges and consequences. Rev Bras Geriatr Gerontol. 2016; 19(3):507-19. doi: https://dx.doi. org/10.1590/1809-98232016019.150140

2. Lopes MC, Lage JS, Campanharo CRV, Okuno MF, Batista RE. Factors associated with functional impairment of elderly patients in the emergency departments. Einstein. 2015; 13(2):209-14. doi: dx.doi.org/10.1590/S1679-45082015A03327

3. Reis LA, Rocha TS, Duarte SFP. Falls: risk and associated factors in institutionalized elderly. Rev Baiana Enferm [Internet]. 2014 [cited 2018 May 15];28(3):225-34. Available from: https:// portalseer.ufba.br/index.php/enfermagem/ article/viewFile/12303/8982

4. Nascimento ERP, Silva SG, Souza BC, Souza DD, Germer Netto. Environment of a hospital emergency unit for the elderly care: perception of nursing professionals. Esc Anna Nery. 2015; 19(2):338-42. doi: dx.doi.org/10.5935/14148145.20150046 
5. Barbosa BR, Almeida JM, Barbosa MR, RossiBarbosa LAR. Evaluation of the functional capacity of the elderly and factors associated with disability. Ciênc Saúde Coletiva. 2014; 19(8):3317-25. doi: dx.doi.org/10.1590/141381232014198.06322013

6. Oliveira-Figueiredo DST, Felisbino-Mendes MS, Malta DC, Velasquez-Melendez G. Prevalência de incapacidade funcional em idosos: análise da Pesquisa Nacional de Saúde. Rev Rene. 2017; 18(4):468-75. doi: dx.doi.org/10.15253/21756783.2017000400007

7. Silveira VC, Paskulin L. Perfil e rede de apoio de idosos internados na emergência do Hospital de Clínicas de Porto Alegre. Estud Interdiscip Envelhec [Internet]. 2014 [citado 2018 maio 15];19(2):377-96. Disponível em: http://www. seer.ufrgs.br/index.php/RevEnvelhecer/article/ view/40025/32752

8. Nagurney JM, Fleischman W, Han L, Leo-Summers L, Allore HG, Gill TM. Emergency department visits without hospitalization are associated with functional decline in older persons. Ann Emerg Med. 2017; 69(4):426-33. doi: http://dx.doi. org/10.1016/j.annemergmed.2016.09.018

9. Goulart LS, Carvalho AC, Lima JC, Pedrosa JM, Lemos PL, Oliveira RB. Consumo de medicamentos por idosos de uma unidade básica de saúde de Rondonópolis/MT. Estud Interdiscip Envelhec [Internet]. 2014 [citado 2018 maio 15];19(1):79-94. Disponível em: http://www.seer.ufrgs.br/index. php/RevEnvelhecer/article/view/25854/31002

10. Fuhrmann AC, Bierhals CCBK, Santos NO, Paskulin LMG. Association between the functional capacity of dependant elderly people and the burden of family caregivers. Rev Gaúcha Enferm. 2015; 36(1):14-20. doi: http://dx.doi. org/10.1590/1983-1447.2015.01.49163

11. Prato SCF, Andrade SM, Cabrera MAS, Dip RM, Santos HG, Dellaroza MSG, et al. Frequency and factors associated with falls in adults aged 55 years or more. Rev Saúde Pública. 2017; 51:37.http://dx.doi.org/10.1590/s15188787.2017051005409
12. Vieira LS, Gomes AP, Bierhals IO, Farías-Antúnez S, Ribeiro CG, Miranda VIA, et al. Falls among older adults in the South of Brazil: prevalence and determinants. Rev Saúde Pública. 2018; 52:22.https://doi.org/10.11606/S15188787.2018052000103

13. Ferretti F , Castanha AC , Padoan ER, Lutinski J , Silva MR Quality of life in the elderly with and without chronic pain. Br J Pain. 2018; 1(2):111-5. doi: dx.doi.org/10.5935/2595-0118.20180022

14. Santana FJ, Lima MCAM. Prevalência de quedas e dor musculoesquelética em idosos. Saúde Meio Ambient [Internet]. 2014 [citado 2018 maio 15]; 3(2):80-9. Disponível em: http://www.periodicos. unc.br/index.php/sma/article/view/618/500

15. Quadros LB, Aguiar A, Menezes AV, Alves EF, Nery T, Bezerra PP. Prevalência de incontinência urinária entre idosos institucionalizados e sua relação com estado mental, independência funcional e comorbidades associadas. Acta Fisiátr. 2015; 22(3):130-4. doi: http://dx.doi. org/10.5935/0104-7795.20150025

16. Abreu HCA, Reiners AAO, Azevedo RCS, Silva AMC, Abreu DROM. Urinary incontinence in the prediction of falls in hospitalized elderly. Rev Esc Enferm USP. 2014; 48(5):851-6. doi: http://dx.doi. org/10.1590/S0080-6234201400005000011

17. Abreu HCA, Reiners AAO, Azevedo RCS, Silva AMC, Abreu DROM, Oliveira AD. Incidence and predicting factors of falls of older inpatients. Rev Saúde Pública. 2015; 49:37. doi: http://dx.doi. org/10.1590/S0034-8910.2015049005549

18. Saraiva VT, Pinheiro LNC, Camacho RLAB, O’Dwyer G, Lima IS, Andrade MKN, Atie S. Prevalence of overburden in caregivers of dependent elderly and associated factors in a poor area of Rio de Janeiro, Brazil. Cad Saúde Pública 2016; 32(6):20. doi: https://doi.org/10.1590/0102$311 \times 00060115$

19. Fhon JRS, Rodrigues RAP, Santos JLF, Diniz MA, Santos EB, et al. Factors associated with frailty in older adults: a longitudinal study. Rev Saúde Pública. 2018; 52:74. doi: http://dx.doi. org/10.11606/S1518-8787.2018052000497 